Research Article

\title{
Study on Mechanical Behavior of Aging Asphalt Based on Composite Regeneration and Modification
}

\author{
Haitao Zhang $(\mathbb{D}$, Ying Wang, Zuoqiang Liu, and Quansheng Sun \\ College of Civil Engineering, Northeast Forestry University, Harbin 150040, China \\ Correspondence should be addressed to Quansheng Sun; hrbsqs@126.com
}

Received 25 August 2019; Revised 31 December 2019; Accepted 21 February 2020; Published 16 March 2020

Academic Editor: Veronica Calado

Copyright (C) 2020 Haitao Zhang et al. This is an open access article distributed under the Creative Commons Attribution License, which permits unrestricted use, distribution, and reproduction in any medium, provided the original work is properly cited.

\begin{abstract}
Although the aging asphalt and its regeneration were researched by many researchers, the poor low-temperature performance of regenerating asphalt has still not been solved yet. In this project, the composite technology of regeneration and modification will be used to solve the problem mentioned above. Through the investigation and analysis on the composite mechanism of regeneration and modification for aging asphalt, the objective of the project attempts to explore a method for the synchronized recovery of high- and low-temperature performance of aging asphalt. The research results show that the single regenerating technology cannot fully recover the low-temperature performance of aging asphalt, and the composite technology of regeneration and modification can make the performance of aging asphalt recovery well. The indexes of aging asphalt after composite regeneration and modification have been recovered, which are better than the indexes of $90 \#$ asphalt $\left(25^{\circ} \mathrm{C}\right.$ penetration is $80-100 /$ $0.1 \mathrm{~mm}$ ) and close with the indexes of styrene-butadiene-styrene (SBS) modified asphalt. The project has demonstrated that the composite technology of regeneration and modification can make the high- and low-temperature performance of aging asphalt recovery well. The research results can obtain better economic and social benefits.
\end{abstract}

\section{Introduction}

Although the aging asphalt and regeneration were researched a lot, the poor low-temperature performance of the regenerating asphalt has still not been solved better yet $[1,2]$. The aging asphalt regeneration, currently, was only emphasized on the balance recovery in the proportion of aging asphalt components, but the stability recovery in the colloidal structure of aging asphalt was ignored $[3,4]$. After regeneration of the aged asphalt, the recovery of small molecules (such as aromatics) in the four components of the asphalt leads to the softening of the asphalt and the weakening of the high-temperature performance. Therefore, the regenerating asphalt mixture will produce more large permanent deformation when it is subjected to load under high-temperature conditions $[5,6]$. However, the colloidal structure of regenerating asphalt has not been recovered well, so the low-temperature performance of asphalt has not been improved well. The ideal regeneration of aging asphalt should be the synchronized recovery both the balance recovery in components proportion and the stability recovery in the colloidal structure of aging asphalt, requiring the recovery not only in quantity (components) but also in quality (colloidal structure) [7]. From analysis on the mechanism of modification technology, the modified agent in modification technology can bind the molecular particles in regenerating asphalt $[8,9]$, so that the macromolecules (such as asphaltene) in regenerating asphalt can be recovered better. Meanwhile, the modification technology can meet the requirement on the recovery of the colloidal structure. So it is necessary to modify asphalt at the same time. When the small molecular components in asphalt (such as aromatics) decrease and the large molecular components (such as asphaltene) increase, the asphalt hardens, the penetration decreases, and the high-temperature performance of asphalt becomes better. When the colloidal structure of asphalt is transformed from gel type to sol type, the fluidity of asphalt becomes better, the colloidal structure becomes stable, the ductility of asphalt increases, and the low-temperature performance becomes better. Therefore, the change of penetration degree is used to represent the recovery of high-temperature performance of 
asphalt, and the ductility is used to represent the recovery of low-temperature performance of asphalt.

In the project, the composite technology of regeneration and modification will be used to solve the problem of the poor low-temperature performance of regenerating asphalt and improve the high-temperature performance of regenerating asphalt at the same time. The objective of this project attempts to explore a method for the synchronized recovery of high- and low-temperature performance of aging asphalt, and the optimal composite regeneration and modification sequence is explored. The findings can be applied in practical reclaimed asphalt pavement (RAP) and can obtain better economic and social benefits.

\section{Regeneration of Aging Asphalt}

2.1. Asphalt Aging. $90 \#$ original asphalt $\left(25^{\circ} \mathrm{C}\right.$ penetration is $80 \sim 100 / 0.1 \mathrm{~mm}$ ) was used in the test. Under the condition of ventilation, an ordinary oven was used to carry out the aging test, and the aging time was $5 \mathrm{~h}$ and $20 \mathrm{~h}$, respectively [10]. By referring to the test procedures of asphalt and asphalt mixture for highway engineering (JTJ052-2011), the performance indexes (penetration, ductility, softening point, and viscosity) of asphalt under different aging time were determined. Three parallel samples were made for each asphalt, and the average value of the data in the effective range was taken as the final value. The test results are shown in Table 1 and Figure 1.

It can be seen from Tables 1 and 2 and Figure 1 the penetration of aging asphalt for 5 and 20 hours becomes smaller compared with that of $90 \#$ original asphalt, the ductility decreased to half of the original index, and the softening point and viscosity had a little increase. The test results have shown that the high-temperature performance of aging asphalt for 5 and 20 hours has increased, but the low-temperature performance has decreased gradually with the increase of aging time.

\subsection{Regeneration of Aging Asphalt}

2.2.1. Regenerating Agent. The regenerating agent used in this experiment is the thermal regenerating agent of asphalt produced by Pan Jin, which has strong polarity. After being added to the asphalt, it can effectively cover the asphaltene and produce chemical reaction at the same time. The indexes of the regenerating agent used in the test are shown in Table 2.

\subsubsection{Determination of Optimum Regenerating Agent} Content. The aging asphalt for 5 and 20 hours has been regenerated by using different contents of regenerating agent $[11,12]$. The performance of the regenerating asphalt has been analyzed by using the indexes of $25^{\circ} \mathrm{C}$ penetration and $5^{\circ} \mathrm{C}$ ductility in order to determine the optimum content of regenerating agent. The indexes of regenerating asphalt in different contents of regenerating agent are shown in Table 3 and Figure 2.
It can be seen from Table 3 and Figure 2 that the best regenerating results of the aging asphalt for 5 and 20 hours have been reached, respectively, at regenerating agent contents of $2.5 \%$ and $6 \%$, which reached the index standards of the original asphalt. Therefore, the optimum contents of regenerating agent for 5 and 20 hours are, respectively, 2.5\% and $6 \%$ (shown in Table 4).

2.2.3. Analysis on Indexes of Aging and Regenerating Asphalt. The indexes of aging and regenerating asphalt are shown in Table 5 and Figure 3.

It can be seen from Table 5 and Figure 3 that the performance of the aging asphalt for 5 and 20 hours can be recovered to some extent; however, the regenerating efficiency has decreased with the increase of aging time. The high-temperature index $\left(25^{\circ} \mathrm{C}\right.$ penetration) of aging asphalt has been recovered better ( 60 to 93 for $5 \mathrm{~h}$ and 27 to 92 for $20 \mathrm{~h})$, while the low-temperature index $\left(5^{\circ} \mathrm{C}\right.$ ductility) of aging asphalt has been recovered worse ( 4.2 to 14.7 for $5 \mathrm{~h}$ and 3.9 to 14.3 for $20 \mathrm{~h}$ ) compared with SBS modified asphalt. The $5^{\circ} \mathrm{C}$ ductility of aging asphalt continues to increase with the increase of the agent content, but $25^{\circ} \mathrm{C}$ penetration increases too much at the same time. Therefore, the single regenerating technology cannot recover the low-temperature performance well for aging asphalt.

\section{Modification of Regenerating Asphalt}

3.1. Modifying Agent. Tenacity-poly-styrene (TPS) modifying agent was used to modify the regenerating asphalt based on the low-temperature performance, and the indexes of TPS modifying agent are shown in Table 6 (by referring to the test procedures of asphalt and asphalt mixture for highway engineering (JTJ052-2011)). TPS is a modifying agent with high viscosity and evenly dispersed into asphalt through the physical methods of mixing and cutting $[13,14]$. The appearance of TPS modifying agent is shown in Figure 4.

\subsection{Modification of Regenerating Asphalt}

3.2.1. Specimen of TPS Modifying Asphalt. The specimen of TPS modifying asphalt was prepared as follows:

(1) Total amount of TPS modifying agent is determined based on the amount of asphalt

(2) TPS modifying agent is mixed with asphalt at a temperature of $170 \sim 180^{\circ} \mathrm{C}$

\subsubsection{Determination of Optimum TPS Modifying Agent} Content. To improve the low-temperature performance of regenerating asphalt, the regenerating asphalt above for 5 and 20 hours (optimum contents of regenerating agent are, respectively, $2.5 \%$ and $6 \%$ ) has been further modified by using the TPS modifying agent $[15,16]$. Through the analysis on the performance of modified regenerating asphalt by the indexes of $25^{\circ} \mathrm{C}$ penetration and $5^{\circ} \mathrm{C}$ ductility, the indexes of modified regenerating asphalt in different modifying agent 
TABLE 1: Indexes of 90\# original asphalt and aging asphalt in different aging time.

\begin{tabular}{lccccc}
\hline Type & Penetration $/ 0.1 \mathrm{~mm}$ & $\mathrm{P}$. index & Ductility/cm & Softening point $\left({ }^{\circ} \mathrm{C}\right)$ & Viscosity/Pa.s \\
\hline Temperature & $25^{\circ} \mathrm{C}$ & - & $55^{\circ} \mathrm{C}$ & - & 44.5 \\
90\# original asphalt & 93 & -0.9 & 9.0 & 49.7 & 0.328 \\
Aging asphalt $(5 \mathrm{~h})$ & 60 & -3.7 & 4.2 & 55.6 & 0.407 \\
Aging asphalt $(20 \mathrm{~h})$ & 27 & -3.6 & 3.9 & 72.8 & 0.760 \\
SBS modified asphalt & 68 & -0.4 & 35 & 1.895 \\
\hline
\end{tabular}

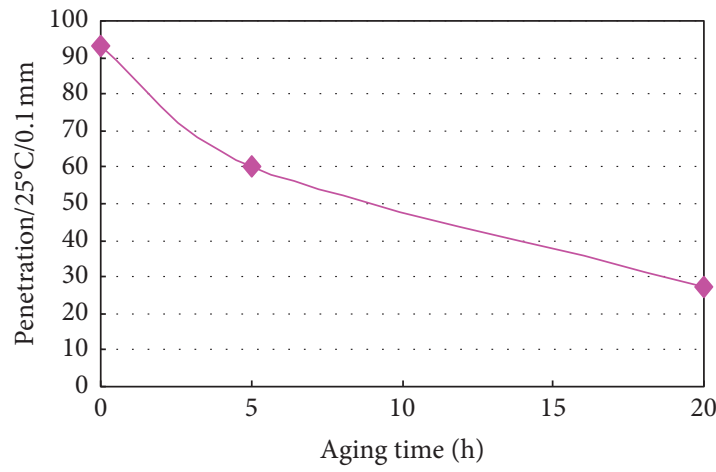

(a)

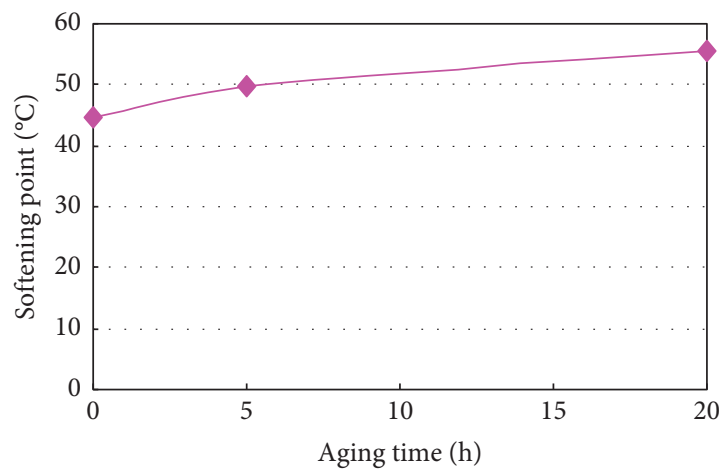

(c)

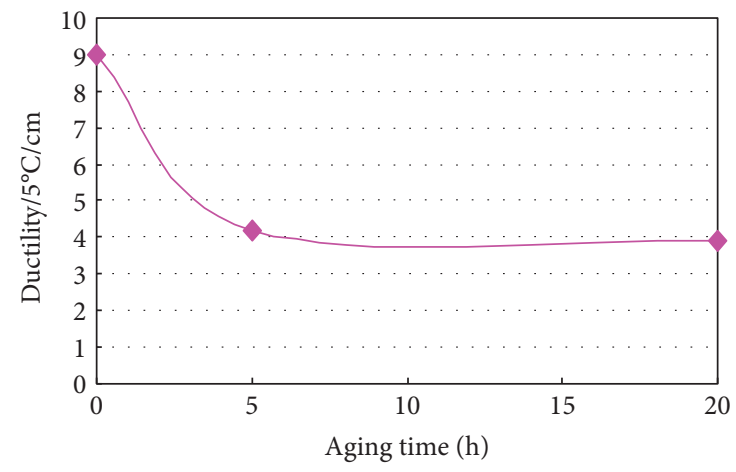

(b)

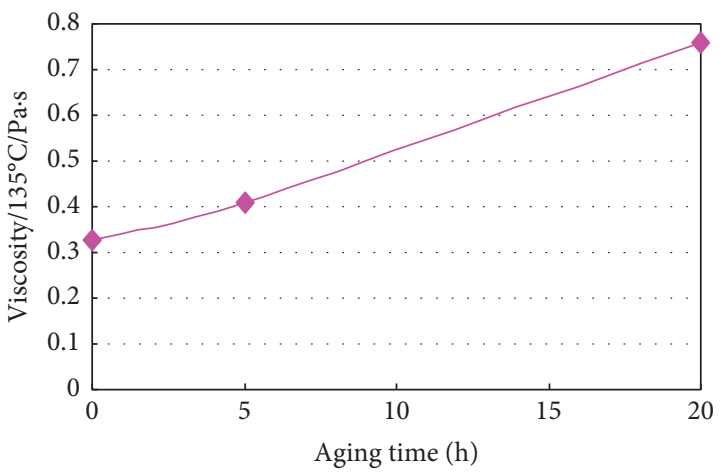

(d)

FIgURE 1: Index curve of aging asphalt in different aging time.

TABLE 2: Indexes of regenerating agent.

\begin{tabular}{lcccc}
\hline Color & Density $\left(\mathrm{g} / \mathrm{cm}^{3}\right)$ & Dynamic viscosity $\left(40^{\circ} \mathrm{C}\right)\left(\mathrm{mm}^{2} / \mathrm{s}\right)$ & Flash point $\left({ }^{\circ} \mathrm{C}\right)$ & Aromatic content $(\%)$ \\
\hline Brown liquid & $1.10 \sim 1.15$ & $15 \sim 35$ & $\geq 230$ & $\geq 80$ \\
\hline
\end{tabular}

TABLE 3: Indexes of regenerating asphalt in different regenerating agent contents.

\begin{tabular}{lccc}
\hline Aging time $(\mathrm{h})$ & Content of regenerating agent $(\%)$ & Penetration $/ 25^{\circ} \mathrm{C} / 0.1 \mathrm{~mm}$ & Ductility $/ 5^{\circ} \mathrm{C} / \mathrm{cm}$ \\
\hline & 0 & 60 & 4.2 \\
5 & 2 & 81 & 8.5 \\
& 2.5 & 93 & 14.7 \\
\hline & 4 & 103 & 21 \\
20 & 0 & 27 & 3.9 \\
& 4 & 68 & 8.8 \\
& 6 & 92 & 14.3 \\
\end{tabular}




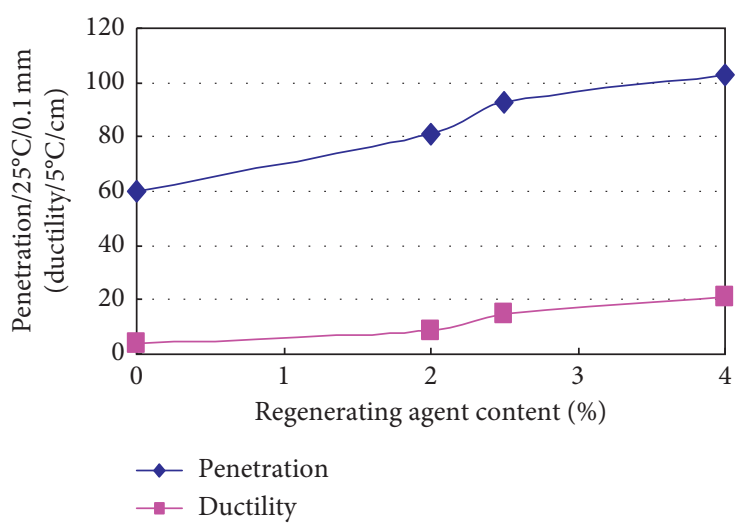

(a)

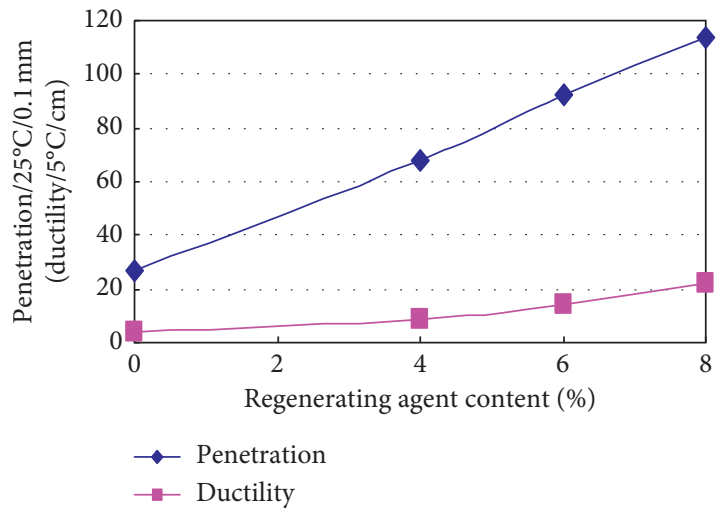

(b)

FIgURE 2: Index curve of regenerating asphalt in different regenerating agent contents.

TABLE 4: Optimum contents of regenerating agent in different aging time.

\begin{tabular}{lc}
\hline Aging time $(\mathrm{h})$ & Optimum regenerating agent content $(\%)$ \\
\hline 5 & 2.5 \\
20 & 6 \\
\hline
\end{tabular}

contents have been tested and are shown in Table 7 and Figure 5.

It can be seen from Table 7 and Figure 5 that the maximum $5^{\circ} \mathrm{C}$ ductility of the modified regenerating asphalt for 5 and 20 hours has been reached at the modifying agent contents of $9 \%$ and $18 \%$. Therefore, the optimum contents of TPS modifying agent for 5 and 20 hours in different aging time are, respectively, $9 \%$ and $18 \%$ (shown in Table 8).

The $5^{\circ} \mathrm{C}$ ductility of the modified regenerating asphalt reached $31.5(35.1) \mathrm{cm}$, and the $25^{\circ} \mathrm{C}$ penetration decreased to 57 (38) $0.1 \mathrm{~mm}$; these values are precise to meet the indexes of SBS modified asphalt (shown in Table 1). Therefore, the regenerating asphalt after modification can meet the requirements of high- and low-temperature performance of asphalt.

\section{Macroperformance of Composite Regenerating and Modifying Asphalt}

4.1. First Regeneration and Then Modification of Aging Asphalt. The regenerating test of the aging asphalt at different aging time ( 5 and $20 \mathrm{~h}$ ) has been conducted first, and then, the modifying test of the regenerating asphalt has been conducted. The test results are shown in Table 9 and Figure 6.

It can be seen from Table 9 and Figure 6, through the first regeneration and then modification, the performance of the aging asphalt for 5 and 20 hours has been recovered well. Compared with the 90\# original asphalt and single regenerating asphalt, the $25^{\circ} \mathrm{C}$ penetration ( 45 for $5 \mathrm{~h}$ and 38 for $20 \mathrm{~h}$ ) is smaller and the $5^{\circ} \mathrm{C}$ ductility ( 31.5 for $5 \mathrm{~h}$ and 30.2 for $20 \mathrm{~h}$ ) is bigger, and the softening point ( 52.0 for $5 \mathrm{~h}$ and 58.0 for $20 \mathrm{~h}$ ) and $135^{\circ} \mathrm{C}$ viscosity $(0.600$ for $5 \mathrm{~h}$ and 0.621 for $20 \mathrm{~h}$ ) are better than those of the 90\# original asphalt and single regenerating asphalt. The test results have shown that the high-temperature performance and low-temperature performance of the asphalt under the composite technology of regeneration and modification (first regeneration and then modification) are better than those of the original and single regenerating asphalt. The problem of poor lowtemperature performance of single regenerating asphalt has been solved. Therefore, the method of composite regeneration and modification technology above for improving the performance of the aging asphalt is feasible.

4.2. First Modification and Then Regeneration of Aging Asphalt. The modifying test of the aging asphalt at different aging time ( 5 and $20 \mathrm{~h}$ ) has been conducted first, and then the regenerating test of the modified asphalt has been conducted. The test results are shown in Table 10 and Figure 7.

It can be seen from Table 10 and Figure 7, through the first modification and then regeneration, the performance of the aging asphalt for 5 and 20 hours has also been recovered well. Compared with the $90 \#$ original asphalt, the $25^{\circ} \mathrm{C}$ penetration ( 60 for $5 \mathrm{~h}$ and 54 for $20 \mathrm{~h}$ ) is smaller and the $5^{\circ} \mathrm{C}$ ductility ( 30.1 for $5 \mathrm{~h}$ and 28.1 for $20 \mathrm{~h}$ ) is bigger, and the softening point (51.9 for $5 \mathrm{~h}$ and 52.7 for $20 \mathrm{~h}$ ) and $135^{\circ} \mathrm{C}$ viscosity ( 0.645 for $5 \mathrm{~h}$ and 0.660 for $20 \mathrm{~h}$ ) are better than those of the 90\# original asphalt. The test results have shown that the high-temperature performance and low-temperature performance of the asphalt under the composite technology of regeneration and modification (first modification and then regeneration) are better than those of the original asphalt. Compared with the single modifying asphalt, the $25^{\circ} \mathrm{C}$ penetration and the $5{ }^{\circ} \mathrm{C}$ ductility of the composite technology of regeneration and modification (first modification and then regeneration) have increased slightly. The high-temperature performance slightly weakened and the low-temperature performance slightly improved. The method of composite regeneration and modification technology above for improving the performance of the aging asphalt is feasible, but worse than that of the first regeneration and then modification. 
TABLE 5: Indexes of aging and regenerating asphalt.

\begin{tabular}{lcccc}
\hline \multirow{2}{*}{ Type } & $\begin{array}{c}\text { Penetration } / 0.1 \mathrm{~mm} \\
25^{\circ} \mathrm{C}\end{array}$ & $\begin{array}{c}\text { Ductility } / \mathrm{cm} \\
5^{\circ} \mathrm{C}\end{array}$ & Softening point $\left({ }^{\circ} \mathrm{C}\right)$ & Viscosity/135 $5^{\circ} \mathrm{C} / \mathrm{Pa} \cdot \mathrm{s}$ \\
\hline 90\# original asphalt & 93 & 9.0 & 44.5 & 0.328 \\
Aging asphalt $(5 \mathrm{~h})$ & 60 & 4.2 & 49.7 & 0.407 \\
Regenerating asphalt $(2.5 \%)(5 \mathrm{~h})$ & 93 & 14.7 & 48.0 & 0.270 \\
\hline 90\# original asphalt & 93 & 9.0 & 44.5 & 0.328 \\
Aging asphalt $(20 \mathrm{~h})$ & 27 & 3.9 & 55.6 & 0.760 \\
Regenerating asphalt $(6 \%)(20 \mathrm{~h})$ & 92 & 14.3 & 50.1 & 0.306 \\
\hline
\end{tabular}

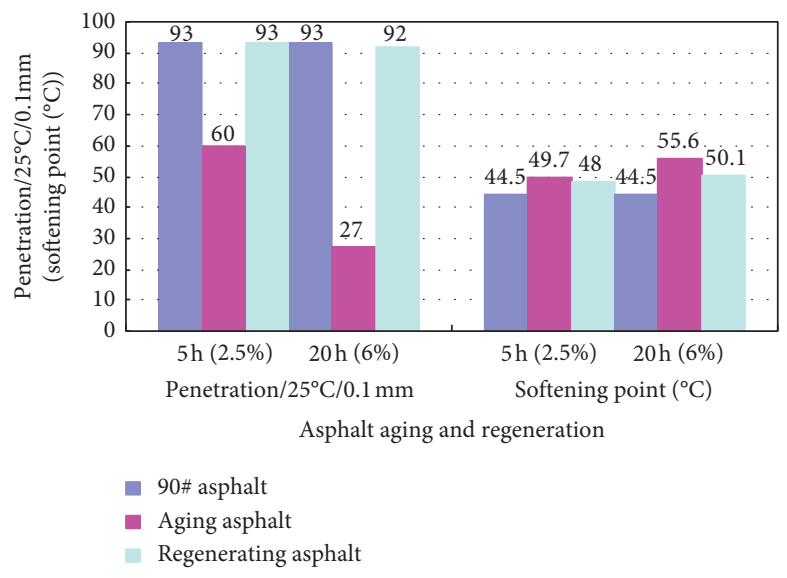

(a)

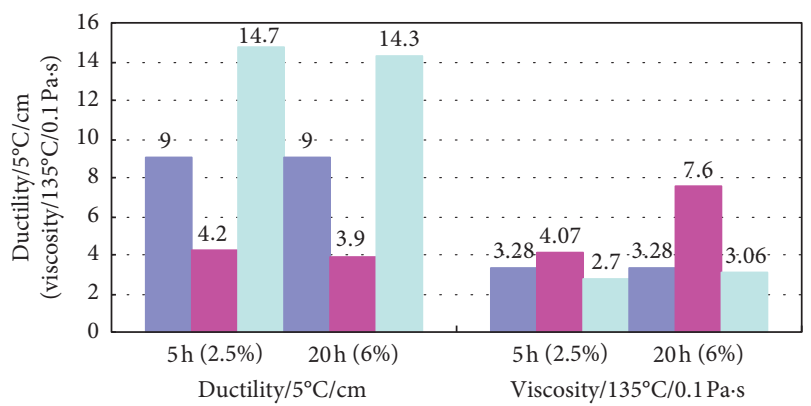

Aspahlt aging and regeneration

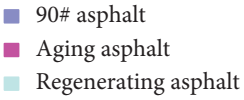

(b)

FIGURE 3: Index relationships of aging and regenerating asphalt.

TABLE 6: Indexes of TPS modifying agent.

\begin{tabular}{lcc}
\hline Indexes & Test results & Standards \\
\hline Particle size $(\mathrm{mm})$ & 4 & $\leq 5$ \\
Density $\left(\mathrm{g} / \mathrm{cm}^{3}\right)$ & 0.9 & $0.7 \sim 1.0$ \\
Water absorption & $0.3 \%$ & $<1 \%$ \\
\hline
\end{tabular}

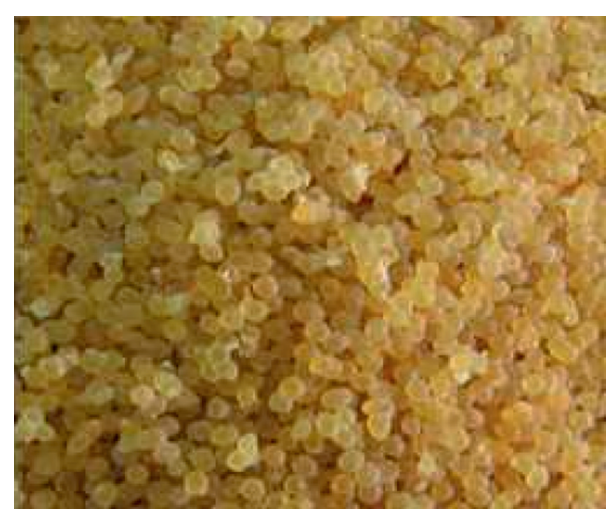

FIGURE 4: TPS modifying agent for camera.

4.3. Regeneration and Modification of Aging Asphalt at the Same Time. The regenerating and modifying test of the aging asphalt at the same time has been conducted. The test results are shown in Table 11 and Figure 8.

It can be seen from Table 11 and Figure 8, through the regeneration and modification at the same time, the performance of the aging asphalt for 5 and 20 hours has also been recovered well, and the composite efficiency is also better than that of the first regeneration and then modification, but slightly worse than that of the first modification and then regeneration. Compared with that, the $25^{\circ} \mathrm{C}$ penetration kept stable ( 62 for $5 \mathrm{~h}$ and 45 for $20 \mathrm{~h}$ ) and the 
TABLE 7: Indexes of modified regenerating asphalt in different modifying agent contents.

\begin{tabular}{|c|c|c|c|c|}
\hline Type & Content of regenerating agent (\%) & Content of TPS modifying agent (\%) & Penetration $/ 25^{\circ} \mathrm{C} / 0.1 \mathrm{~mm}$ & Ductility $/ 5^{\circ} \mathrm{C} / \mathrm{cm}$ \\
\hline \multirow{5}{*}{$5 \mathrm{~h}$} & \multirow{5}{*}{2.5} & - & 60 & 4.2 \\
\hline & & 0 & 93 & 14.7 \\
\hline & & 6 & 70 & 27.3 \\
\hline & & 9 & 57 & 31.5 \\
\hline & & 12 & 62 & 30.5 \\
\hline \multirow{5}{*}{$20 \mathrm{~h}$} & 0 & & 27 & 3.9 \\
\hline & \multirow{4}{*}{6} & 0 & 92 & 14.3 \\
\hline & & 15 & 39 & 28.6 \\
\hline & & 18 & 38 & 35.1 \\
\hline & & 21 & 30 & 33.0 \\
\hline
\end{tabular}

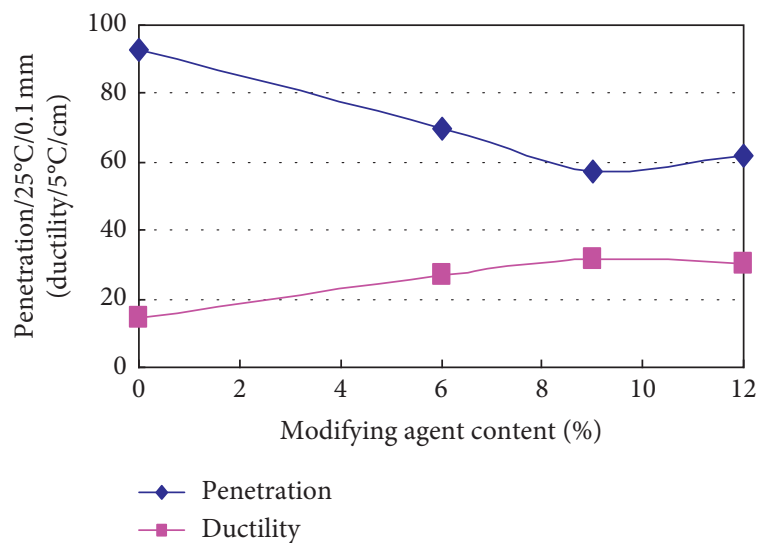

(a)

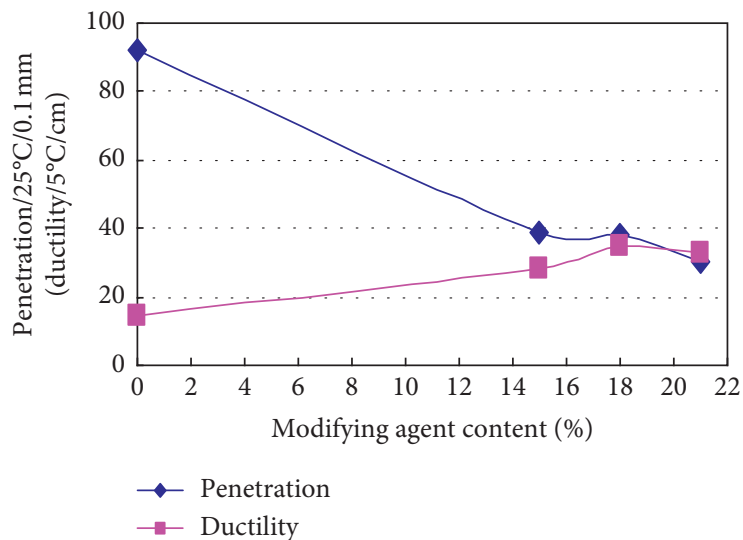

(b)

FIGURE 5: Index curve of modified regenerating asphalt in different modifying agent contents.

TABLE 8: Optimum modifying agent content in different aging time.

\begin{tabular}{lcc}
\hline Aging time $(\mathrm{h})$ & Optimum regenerating agent content $(\%)$ & Optimum TPS modifying agent content (\%) \\
\hline 5 & 2.5 & 9 \\
20 & 6 & 18 \\
\hline
\end{tabular}

TABLE 9: Indexes of first regeneration and then modification of aging asphalt.

\begin{tabular}{|c|c|c|c|c|}
\hline Type & $\begin{array}{c}\text { Penetration } / 0.1 \mathrm{~mm} \\
25^{\circ} \mathrm{C} \\
\end{array}$ & $\begin{array}{c}\text { Ductility/cm } \\
5^{\circ} \mathrm{C} \\
\end{array}$ & Softening point $\left({ }^{\circ} \mathrm{C}\right)$ & Viscosity $/ 135^{\circ} \mathrm{C} / \mathrm{Pa} \cdot \mathrm{s}$ \\
\hline 90\# original asphalt & 93 & 9.0 & 44.5 & 0.328 \\
\hline Aging asphalt $(5 \mathrm{~h})$ & 60 & 4.2 & 49.7 & 0.407 \\
\hline Regenerating asphalt $(2.5 \%)(5 \mathrm{~h})$ & 93 & 14.7 & 48.0 & 0.270 \\
\hline Modified regenerating asphalt (9\%) (5h) & 45 & 31.5 & 52.0 & 0.600 \\
\hline 90\# original asphalt & 93 & 9.0 & 44.5 & 0.328 \\
\hline Aging asphalt $(20 \mathrm{~h})$ & 27 & 3.9 & 55.6 & 0.760 \\
\hline Regenerating asphalt (6\%) (20 h) & 92 & 14.3 & 50.1 & 0.306 \\
\hline Modified regenerating asphalt $(18 \%)(20 \mathrm{~h})$ & 38 & 30.2 & 58.0 & 0.621 \\
\hline
\end{tabular}

$5^{\circ} \mathrm{C}$ ductility slightly decreased $(26.0$ for $5 \mathrm{~h}$ and 23.0 for $20 \mathrm{~h}$ ), and the softening point and $135^{\circ} \mathrm{C}$ viscosity also slightly decreased $(47.7,0.260$ for $5 \mathrm{~h}$ and $50.1,0.438$ for $20 \mathrm{~h}$ ). Therefore, the test results have shown that the method above for improving the performance of the aging asphalt is also feasible. Through analysis on the 3 methods above, it is suggested that the method of the first regeneration and then modification is the best technology.
4.4. Comparative Analysis on the Test Results. The above 3 test results of regeneration and modification about aging asphalt are shown in Table 12 and Figure 9.

From Table 12 and Figure 9, during the process of composite regeneration and modification, the following results can be obtained:

(1) The indexes of $25^{\circ} \mathrm{C}$ penetration increased by regenerating agent but decreased by modifying 


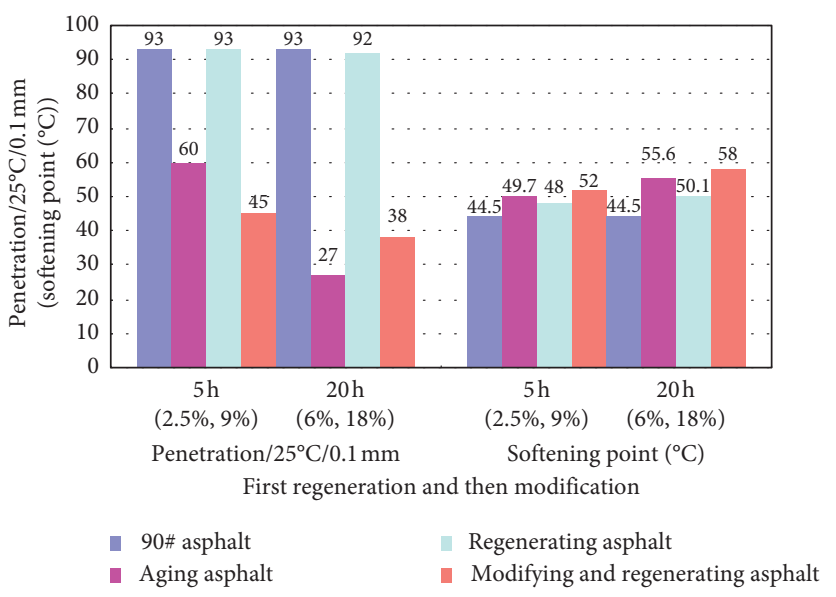

(a)

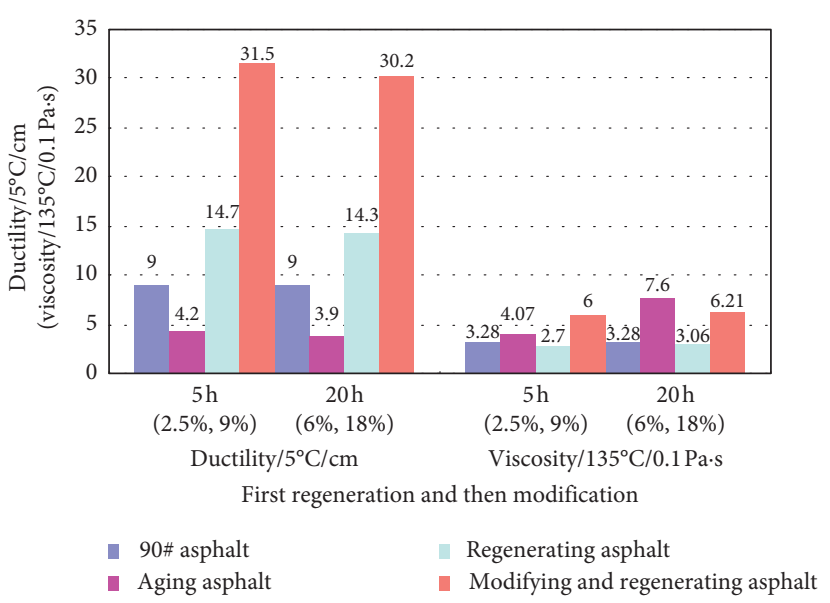

(b)

FIGURE 6: Index relationships of first regeneration and then modification of aging asphalt.

TABLE 10: Indexes of first modification and then regeneration of aging asphalt.

\begin{tabular}{lcccc}
\hline Type & $\begin{array}{c}\text { Penetration } / 0.1 \mathrm{~mm} \\
25^{\circ} \mathrm{C}\end{array}$ & $\begin{array}{c}\text { Ductility/cm } \\
5^{\circ} \mathrm{C}\end{array}$ & Softening point $\left({ }^{\circ} \mathrm{C}\right)$ & Viscosity/135 $5^{\circ} \mathrm{C} / \mathrm{Pa} \cdot \mathrm{s}$ \\
\hline 90\# original asphalt & 93 & 9.0 & 44.5 & 0.328 \\
Aging asphalt (5 h) & 60 & 4.2 & 49.7 & 0.407 \\
Modified asphalt (9\%) (5 h) & 33 & 29.5 & 54.7 & 0.775 \\
Regenerating modified asphalt (2.5\%) (5h) & 60 & 31.0 & 51.9 & 0.645 \\
\hline 90\# original asphalt & 93 & 9.0 & 44.5 & 0.328 \\
Aging asphalt (20 h) & 27 & 3.9 & 55.6 & 0.760 \\
Modified asphalt (18\%) (20 h) & 19 & 24.1 & 52.7 & 1.070 \\
Regenerating modified asphalt (6\%) $(20 \mathrm{~h})$ & 54 & 28.1 & & 0.660 \\
\hline
\end{tabular}

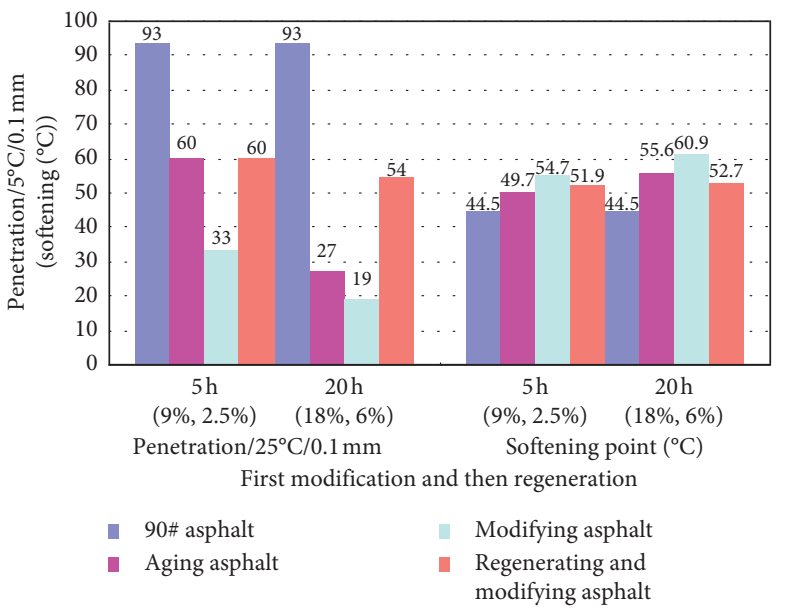

(a)

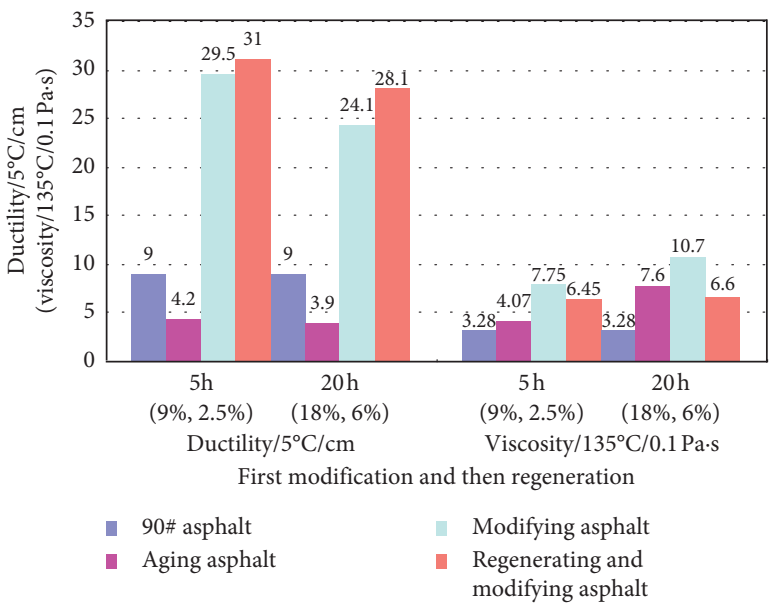

(b)

Figure 7: Index relationships of first modification and then regeneration of aging asphalt.

agent. The indexes of $25^{\circ} \mathrm{C}$ penetration after composite regeneration and modification are close with those of SBS modified asphalt.

(2) The indexes of $5^{\circ} \mathrm{C}$ ductility increased by both regenerating agent and modifying agent. The indexes of $5^{\circ} \mathrm{C}$ ductility after composite regeneration and modification in 3 methods are close and basically the same as SBS modified asphalt.

(3) The indexes of softening point and $135^{\circ} \mathrm{C}$ viscosity after composite regeneration and modification in 3 methods are basically the same, but have a certain gap with SBS modified asphalt. 
TABLE 11: Indexes of regenerating and modifying test of aging asphalt at the same time.

\begin{tabular}{|c|c|c|c|c|}
\hline Type & $\begin{array}{c}\text { Penetration/ } \\
0.1 \mathrm{~mm} \\
25^{\circ} \mathrm{C} \\
\end{array}$ & $\begin{array}{c}\text { Ductility/ } \\
\mathrm{cm} \\
5^{\circ} \mathrm{C} \\
\end{array}$ & $\begin{array}{l}\text { Softening point } \\
\left({ }^{\circ} \mathrm{C}\right)\end{array}$ & $\begin{array}{c}\text { Viscosity } / 135^{\circ} \mathrm{C} / \\
\mathrm{Pa} \cdot \mathrm{s}\end{array}$ \\
\hline 90\# original asphalt & 93 & 9.0 & 44.5 & 0.328 \\
\hline Aging asphalt $(5 \mathrm{~h})$ & 60 & 4.2 & 49.7 & 0.407 \\
\hline $\begin{array}{l}\text { Regenerating and modifying asphalt at the same time } \\
(2.5 \%+9 \%)(5 \mathrm{~h})\end{array}$ & 62 & 26.0 & 47.7 & 0.260 \\
\hline 90\# original asphalt & 93 & 9.0 & 44.5 & 0.328 \\
\hline Aging asphalt $(20 \mathrm{~h})$ & 27 & 3.9 & 55.6 & 0.760 \\
\hline $\begin{array}{l}\text { Regenerating and modifying asphalt at the same time } \\
(6 \%+18 \%)(20 \mathrm{~h})\end{array}$ & 45 & 23.0 & 50.1 & 0.438 \\
\hline
\end{tabular}

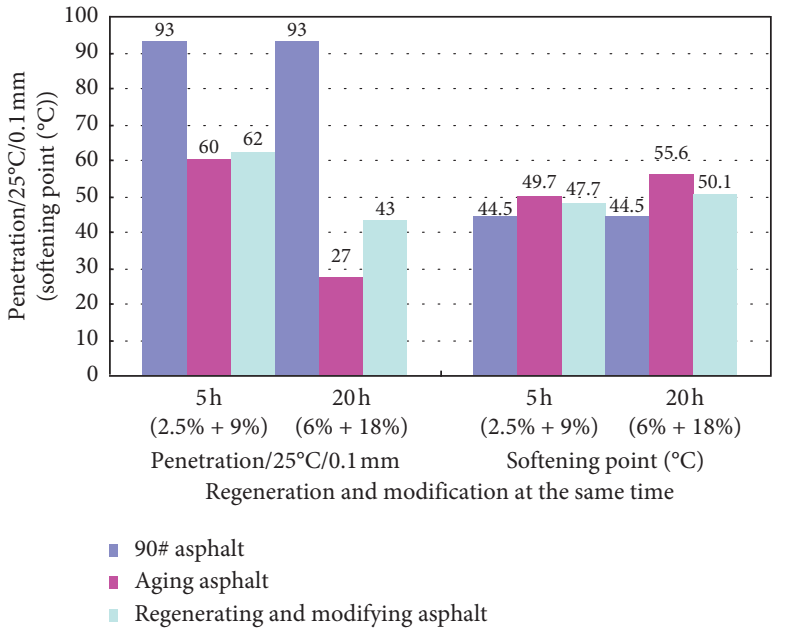

(a)

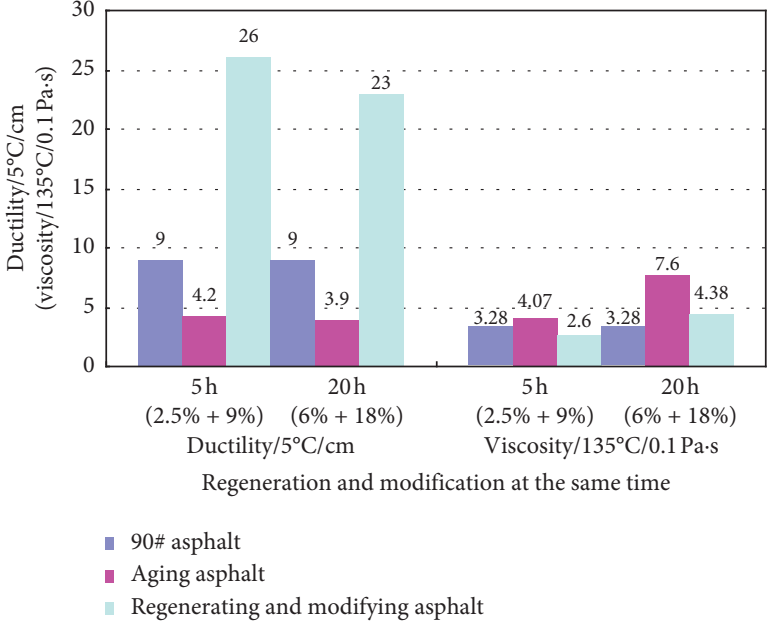

(b)

FIGURE 8: Index relationships of regenerating and modifying test of aging asphalt at the same time.

TABLE 12: Index comparisons of regeneration and modification about aging asphalt.

\begin{tabular}{|c|c|c|c|c|}
\hline Type & $\begin{array}{c}\text { Penetration/ } \\
0.1 \mathrm{~mm} \\
25^{\circ} \mathrm{C}\end{array}$ & $\begin{array}{c}\text { Ductility/ } \\
\mathrm{cm} \\
5^{\circ} \mathrm{C} \\
\end{array}$ & $\begin{array}{l}\text { Softening point } \\
\quad\left({ }^{\circ} \mathrm{C}\right)\end{array}$ & $\begin{array}{l}\text { Viscosity } / 135^{\circ} \mathrm{C} / \\
\mathrm{Pa} \cdot \mathrm{s}\end{array}$ \\
\hline 90\# original asphalt & 93 & 9.0 & 44.5 & 0.328 \\
\hline Aging asphalt $(5 \mathrm{~h})$ & 60 & 4.2 & 49.7 & 0.407 \\
\hline $\begin{array}{l}\text { First regenerating and then modifying asphalt }(2.5 \% \longrightarrow 9 \%) \\
(5 \mathrm{~h})\end{array}$ & 45 & 31.5 & 52.0 & 0.600 \\
\hline $\begin{array}{l}\text { First modifying and then regenerating asphalt }(9 \% \longrightarrow 2.5 \%) \\
(5 \mathrm{~h})\end{array}$ & 60 & 31.0 & 51.9 & 0.645 \\
\hline $\begin{array}{l}\text { Regenerating and modifying asphalt at the same time } \\
(2.5 \%+9 \%)(5 \mathrm{~h})\end{array}$ & 62 & 26.0 & 47.7 & 0.260 \\
\hline 90\# original asphalt & 93 & 9.0 & 44.5 & 0.328 \\
\hline Aging asphalt $(20 \mathrm{~h})$ & 27 & 3.9 & 55.6 & 0.760 \\
\hline $\begin{array}{l}\text { First regenerating and then modifying asphalt }(6 \% \longrightarrow 18 \%) \\
(20 \mathrm{~h})\end{array}$ & 38 & 30.2 & 58.0 & 0.621 \\
\hline $\begin{array}{l}\text { First modifying and then regenerating asphalt }(18 \% \longrightarrow 6 \%) \\
(20 \mathrm{~h})\end{array}$ & 54 & 28.1 & 52.7 & 0.660 \\
\hline $\begin{array}{l}\text { Regenerating and modifying asphalt at the same time } \\
(6 \%+18 \%)(20 \mathrm{~h})\end{array}$ & 45 & 23.0 & 50.1 & 0.438 \\
\hline
\end{tabular}

In summary, the performance of aging asphalt after composite regeneration and modification has been recovered well and is better than that of 90\# original asphalt and close with SBS modified asphalt. During the process of composite regeneration and modification, the efficiency of first regeneration and then modification is the best, and 


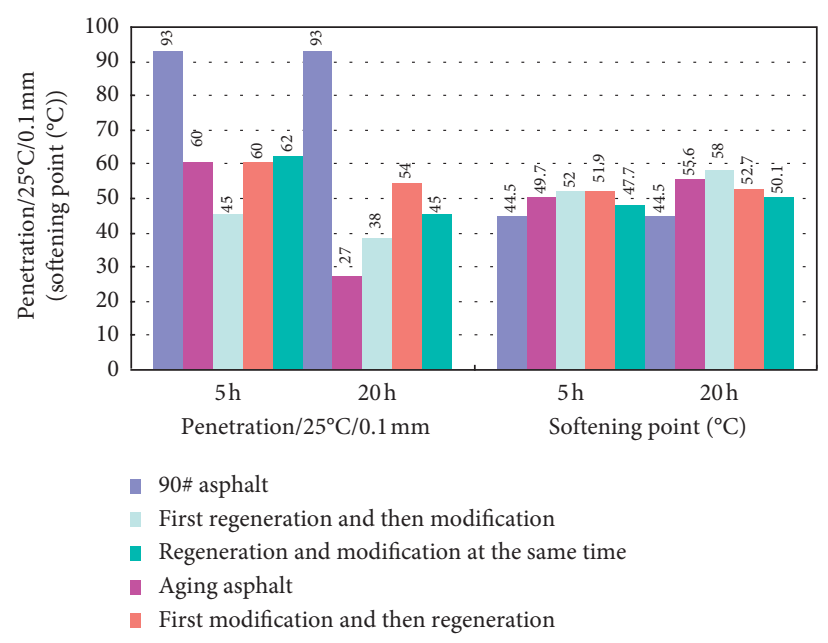

(a)

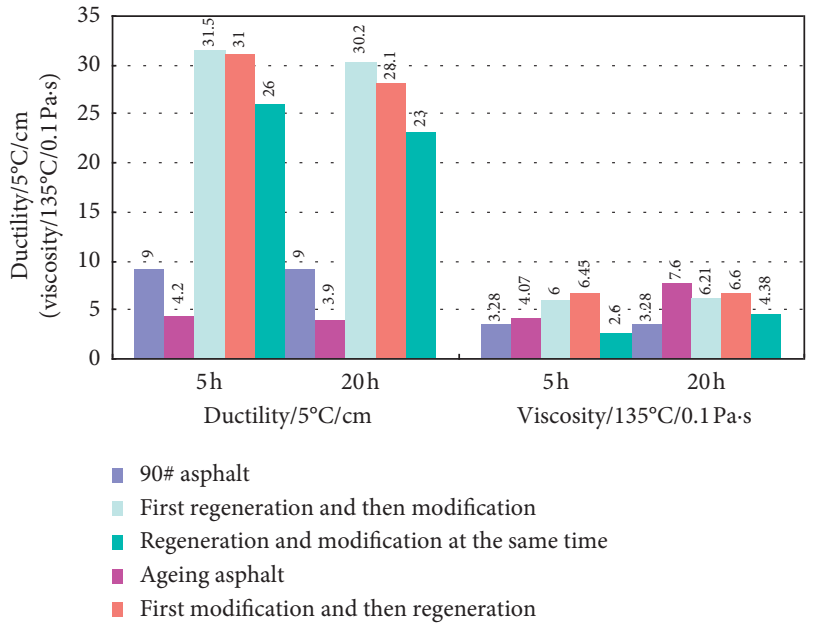

(b)

FIGURE 9: Index relationships of aging asphalt regeneration and modification.

TABLE 13: Results of asphalt component test.

\begin{tabular}{|c|c|c|c|c|}
\hline & \multicolumn{4}{|c|}{ Asphalt component content (\%) } \\
\hline & Saturates & Aromatics & Resins & Asphaltenes \\
\hline 90\# original asphalt & 20.0 & 29.5 & 41.5 & 7.6 \\
\hline Aging asphalt $(5 \mathrm{~h})$ & 19.7 & 26.1 & 38.2 & 10.3 \\
\hline Aging asphalt $(20 \mathrm{~h})$ & 17.2 & 25.0 & 37.8 & 14.9 \\
\hline Regenerating and modifying asphalt at the same time $(5 \mathrm{~h})$ & 19.8 & 27.9 & 39.3 & 9.4 \\
\hline Regenerating and modifying asphalt at the same time $(20 \mathrm{~h})$ & 17.4 & 27.3 & 37.9 & 12.2 \\
\hline
\end{tabular}

followed by first modification and then regeneration, and the efficiency of regeneration and modification of aging asphalt at the same time is worse. Through further analysis on the 3 methods, it is suggested that the technology of first regeneration and then modification should be applied in reclaimed asphalt pavement (RAP).

\section{Microperformance of Composite Regenerating and Modifying Asphalt}

5.1. Component Test. Based on the macromechanism of composite regeneration and modification of aging asphalt, the micromechanism has been further researched [17-19]. By referring to the test procedures of asphalt and asphalt mixture for highway engineering (JTJ052-2011), the component test of composite regenerating and modifying asphalt has been conducted and the test results are shown in Table 13 and Figure 10.

It can be seen from Table 13 and Figure 10, with the increase of aging time (from 5 to $20 \mathrm{~h}$ ), the content of asphaltenes increased, the content of resins almost unchanged, and the contents of both saturates and aromatics decreased. The components of aging asphalt for $5 \mathrm{~h}$ and $20 \mathrm{~h}$ have been recovered through the composite regeneration and modification; however, the content of asphaltenes for $20 \mathrm{~h}$ is much higher than that of 90\# original asphalt.
5.2. SEM Test. The scanning electron microscope (SEM) mainly uses secondary electronic signal imaging to observe the surface morphology of the sample, that is, scanning the sample with extremely narrow electron beam and generating various effects through the interaction between the electron beam and the sample, mainly the secondary electron emission of the sample. SEM test of composite regenerating and modifying asphalt has been conducted, and the test results are shown in Figure 11.

From Figure 11, the following results have been obtained:

(1) The surface of 90\# asphalt in SEM photo (a) is smooth and has few white spots, but there are the obvious traces on the surface of SBS modified 90\# asphalt in SEM photo (b); it is the SBS modifying agent distributed in the asphalt.

(2) In SEM photo (c), there are more solid markings on the surface of $5 \mathrm{~h}$ aging asphalt compared with 90\# asphalt; it is close with the macroperformance of $5 \mathrm{~h}$ aging asphalt. Compared with $5 \mathrm{~h}$ aging asphalt, there are more solid markings on the surface of $20 \mathrm{~h}$ aging asphalt in SEM photo (d), and it is relatively consistent with the two kinds of aging asphalt.

(3) In SEM photo (e) and (f), through the composite regeneration and modification, the solid markings on the surface of $5 \mathrm{~h}$ and $20 \mathrm{~h}$ aging asphalt were 


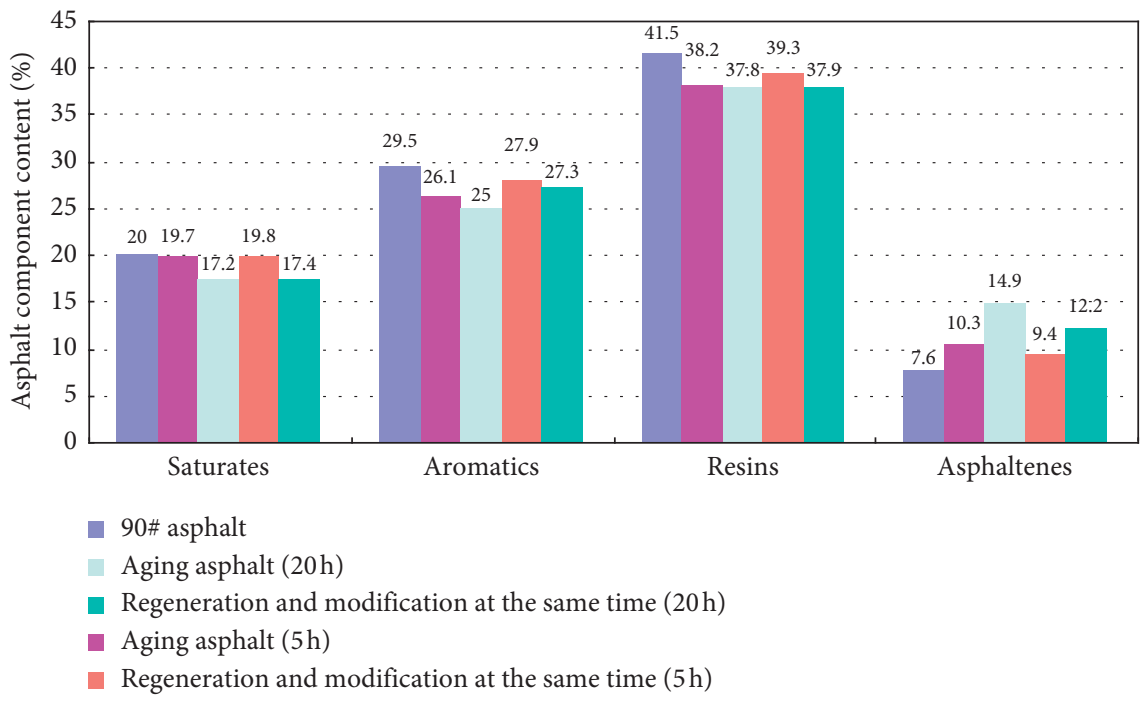

Figure 10: Asphalt component relationships in different aging time.

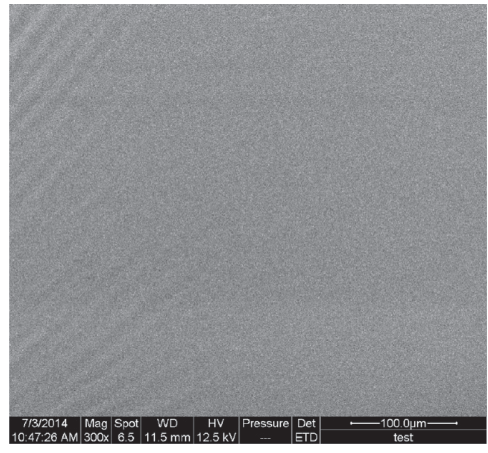

(a)

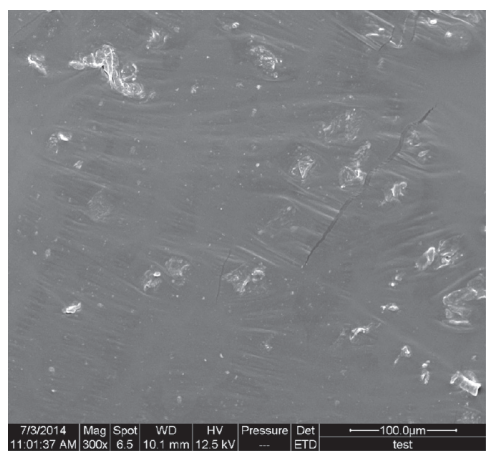

(d)

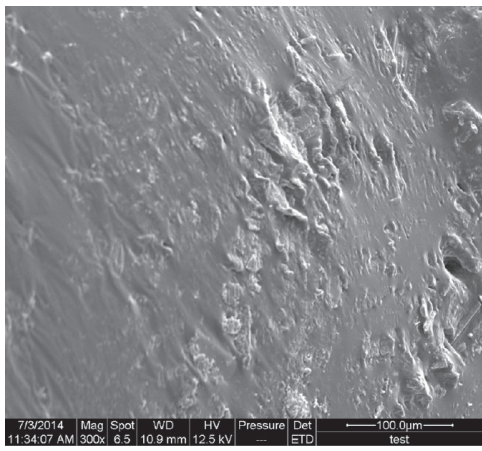

(b)

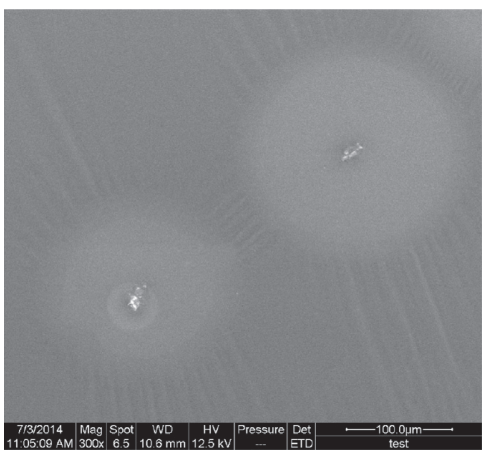

(e)

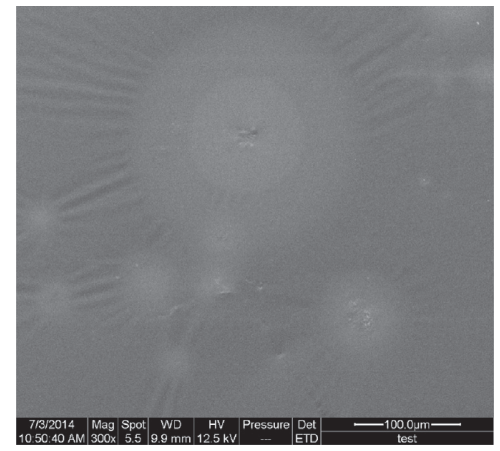

(c)

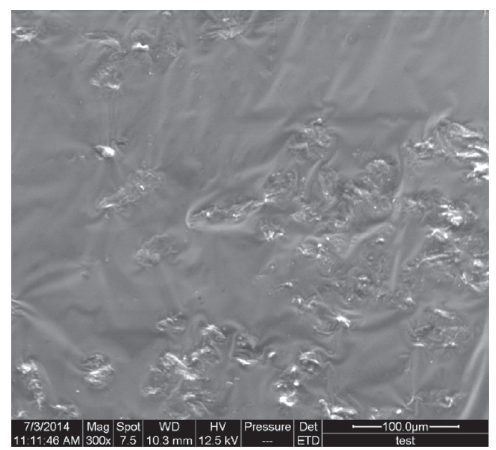

(f)

Figure 11: SEM photos of composite regenerating and modified asphalt. (a) 90\# original asphalt. (b) SBS modified asphalt. (c) Aging asphalt (5h). (d) Aging asphalt (20 h). (e) Regenerating asphalt (5h). (f) Regenerating asphalt (20 h).

distributed uniformly, and it is relatively close with the macroperformance of the 90\# asphalt and SBS modified asphalt.

\section{Conclusions}

(1) The performance of aging asphalt was influenced by the different order during the process of composite regeneration and modification. The efficiency of first regeneration and then modification is the best and followed by first modification and then regeneration, and the efficiency of regeneration and modification of aging asphalt at the same time is worse. Therefore, it is suggested that the technology of first regeneration and then modification should be applied in reclaimed asphalt pavement (RAP).

(2) The asphalt SEM photos have shown that the solid markings on the surface of $5 \mathrm{~h}$ and $20 \mathrm{~h}$ aging asphalt 
have been distributed uniformly after composite regeneration and modification, and it is relatively consistent with the macroperformance of the 90\# asphalt and SBS modified asphalt.

(3) Both single regenerating agent and modifying agent cannot recover the high- and low-temperature performance of aging asphalt at the same time, while the composite technology of regeneration and modification can make the two indexes recovery well. This study has solved the problems of lowtemperature performance in the single regeneration. The findings can be applied in practical reclaimed asphalt pavement (RAP) and can obtain better economic and social benefits.

\section{Data Availability}

The data used to support the findings of this study have not been made available.

\section{Conflicts of Interest}

The authors declare that they have no conflicts of interest.

\section{Acknowledgments}

The authors gratefully appreciate the supports from the province key laboratory of road in Northeast Forestry University and the foundations for the project of National Natural Science Foundation of China (E080703) and the project of Heilongjiang Traffic and Transportation Department.

\section{References}

[1] P. Juristyarini, R. Davison, and C. J. Glover, "Development of an asphalt aging procedure to assess long-term binder performance," Petroleum Science and Technology, vol. 29, no. 21, pp. 2258-2268, 2011.

[2] A. Shenoy, "A method to estimate the rheological properties of aged asphalt binders without actually aging them," Road Materials and Pavement Design, vol. 3, no. 3, pp. 331-343, 2002.

[3] A. M. Baptista, L. G. Picado-Santos, and S. D. Capitão, "Design of hot-mix recycled asphalt concrete produced in plant without preheating the reclaimed material," International Journal of Pavement Engineering, vol. 14, no. 2, pp. 95-102, 2013.

[4] T. B. Alam, M. Abdelrahman, and S. A. Schram, "Laboratory characterisation of recycled asphalt pavement as a base layer," International Journal of Pavement Engineering, vol. 11, no. 2, pp. 123-131, 2010.

[5] F. Dong, X. Yu, B. Xu, and T. Wang, "Comparison of high temperature performance and microstructure for foamed WMA and HMA with RAP binder," Construction and Building Materials, vol. 134, pp. 594-601, 2017.

[6] H. Wang, X. Li, J. Xiao, Z. You, X. Yang, and M. Irfan, "Hightemperature performance and workability of crumb rubbermodified warm-mix asphalt," Journal of Testing and Evaluation, vol. 48, no. 4, 2020.

[7] J. Ji, Study on performance of recycled asphalt and mixture, Tongji University, Shanghai, China, Ph.D. dissertation, 2007.
[8] W. A. Zeiada, K. E. Kaloush, B. S. Underwood, and M. E. Mamlouk, "Improved method of considering air void and asphalt content changes on long-term performance of asphalt concrete pavements," International Journal of Pavement Engineering, vol. 15, no. 8, pp. 718-730, 2014.

[9] J. A. Shen, The Performance of Bitumen and Bituminous Mixtures, China Communication Press, Beijing, China, 2001.

[10] Ministry of Communication, Standard Test Methods of Bitumen and Bituminous Mixtures for Highway Engineering (JTG E20-2011), China Communication Press, Beijing, China, 2011.

[11] H. T. Zhang and J. X. He, "Study on the critical state and limit state of asphalt aging," Journal of Petrochemical Universities, vol. 25, no. 4, pp. 1-5, 2012.

[12] Ministry of Communication, Technical Specifications for Highway Asphalt Pavement Recycling (JTG F41-2008), China Communication Press, Beijing, China, 2008.

[13] L. Y. Chen, "The development of high-viscosity modified asphalt," Dalian University of Technology, Dalian, China, M.S. dissertation, 2012.

[14] Z. G. Zhou, "Recycling behavior of recycling agent on aged asphalt," Journal of Traffic and Transportation Engineering, vol. 11, no. 6, pp. 10-16, 2011.

[15] D. L. Kuang, "Effect of rejuvenator on properties of aged bitumen of different aging degree," Highway, vol. 5, pp. 153-157, 2011.

[16] X. Z. Zhao, "Colloidal states of regenerated asphalt," Journal of Petrochemical Universities, vol. 17, no. 4, pp. 15-19, 2004.

[17] A. N. Zhou and J. Zhu, "Changes of compositions and molecular weight distributions of asphalt for pavement during aging," Journal of Anhui University of Technology, vol. 18, no. 4, pp. 347-350, 2001.

[18] Y. H. Nie, P. Liu, Z. G. Zhou, Y. J. Hou, and X. Dai, "Research on asphalt recycling mechanism based on different recycling agents," Highway Engineering, vol. 37, no. 6, pp. 65-68, 2012.

[19] M. Qi and X. T. Zhang, "Study on performance of recycling modified asphalt mixture," Journal of BUCEA, vol. 27, no. 1, pp. 60-64, 2011. 